\title{
Successful removal of permanent spinal cord stimulators in patients with complex regional pain syndrome after complete relief of pain
}

\author{
${ }^{1}$ Department of Anesthesia and Pain Medicine, School of Medicine, Pusan National University, Yangsan, Korea \\ ${ }^{2}$ Department of Pain Medicine, Division of Anesthesia and Critical Care, The University of Texas MD Anderson Cancer Center, \\ Houston, TX, USA \\ Su Jung Lee', Yeong Min Yoo', Jun A You', Sang Wook Shin', \\ Tae Kyun Kim', Salahadin $\mathrm{Abdi}^{2}$, and Kyung Hoon Kim ${ }^{1}$
}

Background: It is uncommon for patients who have received a permanent implant to remove the spinal cord stimulator (SCS) after discontinuation of medication in complex regional pain syndrome (CRPS) due to their completely painless state. This study evaluated CRPS patients who successfully removed their SCSs.

Methods: This 10-year retrospective study was performed on patients who had received the permanent implantation of an SCS and had removed it 6 months after discontinuation of stimulation, while halting all medications for neuropathic pain. Age, sex, duration of implantation, site and type of CRPS, and their return to work were compared between the removal and non-removal groups.

Results: Five $(12.5 \%, \mathrm{M} / \mathrm{F}=4 / 1)$ of 40 patients $(\mathrm{M} / \mathrm{F}=33 / 7)$ successfully removed the permanent implant. The mean age was younger in the removal group $(27.2 \pm 6.4$ vs. $43.5 \pm 10.7$ years, $P<0.01)$. The mean duration of implantation in the removal group was $34.4 \pm 18.2$ months. Two of 15 patients (13.3\%) and 3 of 25 patients (12\%) who had upper and lower extremity pain, respectively, had removed the implant. The implants could be removed in 5 of 27 patients $(18.5 \%)$ with CRPS type $1(P<0.01)$. All 5 patients $(100 \%)$ who removed their SCS returned to work, while only 5 of 35 (14.3\%) in the non-removal group did $(P<$ $0.01)$.

Conclusions: Even though this study had limited data, younger patients with CRPS type 1 could remove their SCSs within a 5-year period and return to work with complete pain relief. (Korean J Pain 2019; 32: 47-50)

Key Words: Age factors; Complex regional pain syndrome; Device removal; Extremities; Humans; Neuropathic pain; Retrospective studies; Return to work; Spinal cord stimulation.

Received November 22, 2018. Revised December 11, 2018. Accepted December 11, 2018

Correspondence to: Kyung Hoon Kim

Department of Anesthesia and Pain Medicine, School of Medicine, Pusan National University, 20 Geumo-ro, Mulgeum-eup, Yangsan 50612, Korea

Tel: +82-55-360-1422, Fax: +82-55-360-2149, E-mail: pain@pusan.ac.kr

(ㄷ) This is an open-access article distributed under the terms of the Creative Commons Attribution Non-Commercial License (http:// creativecommons.org/licenses/by-nc/4.0/), which permits unrestricted non-commercial use, distribution, and reproduction in any medium, provided the original work is properly cited.

Copyright (c) The Korean Pain Society, 2019 


\section{INTRODUCTION}

Traditionally, complex regional pain syndrome has been treated with medication, using an anticonvulsant and an antidepressant with a weak opioid for neuropathic pain, thoracic or lumbar sympathectomy for cold allodynia, and a spinal cord stimulator (SCS), if these treatments have failed.

However, it is uncommon to find full recovery from the pain of CRPS. Full recovery from the pain of CRPS in this study was defined as a painless state after the removal of the SCS even after reduction and final cessation of all medication and complete cessation of the SCS for at least 6 months.

Use of an SCS for the treatment of CRPS was considered a last resort therapy because of its high cost and level of invasiveness. However, it is now considered earlier (at around 3 months), as soon as more conservative therapies have failed [1].

This study evaluated patients who successfully removed the SCS in CRPS cases retrospectively according to age, sex, type of CRPS, involved extremity, duration between an initiating noxious event to implantation, and duration of implantation of the SCS.

\section{MATERIALS AND METHODS}

\section{Study design, setting, and participants}

A review of the charts of all patients who underwent implantation during a 10-year period, from 2003 to 2013, was performed on CRPS patients who had received the permanent implantation of an SCS and had removed it 6 months after discontinuation of stimulation, while halting all medications for neuropathic pain (IRB 05-2018-048).

The CRPS was diagnosed by the Budapest clinical diagnostic criteria and a positive typical (increase of the uptake in all of blood flow, blood pool, and delayed phases in the early phase of CRPS) and atypical (increased uptake only on the delayed phase with normal or decreased uptake on the flow and blood pool phases in the late phase of CRPS or in young CRPS patients with paralysis and immobilization, respectively) patterns of in 3-phase bone scans [2,3].

The exclusion criterion was patients with less than a 6-month discontinuation of stimulation after halting all medications for neuropathic pain.

\section{Variables}

Patients were divided into removal and non-removal groups. Age at the time of implantation (year), sex (M/F), site and type of CRPS (1 or 2), and their returning to work (yes or no) were compared between the removal and non-removal groups. Durations (months) between an initiating noxious event to implantation and duration of implantation (months) between the removal and non-removal groups were also evaluated.

\section{Statistical methods}

Demographic data included age and sex distribution of the total number and the number of each group in the removal and non-removal group who had received a permanent SCS. The mean age in both groups was compared, using an independent $t$-test. The gender ratio in both groups was compared using the chi-squared test.

The site and type of CRPS, and their returning to work (yes or no), were calculated as a percentile from each group, and compared both groups analyzed with the chi-squared test.

The mean durations (months) of between an initiating event and implantation were compared between the removal and non-removal groups.

The mean duration of implantation (months) in the removal group were calculated.

A $P$ value less than 0.05 was considered statistically significant. The statistical analyses were performed using SPSS 23 (IBM Corporation, Armonk, New York).

\section{RESULTS}

Five $(12.5 \%, M / F=4 / 1)$ among the 40 patients $(M / F=33 / 7)$ successfully removed the permanent implant. The mean age was younger in the removal group than the non-removal group $(27.2 \pm 6.4$ vs. $43.5 \pm 10.7$ years, $P<0.01)$ (Table 1). Two of 15 patients (13.3\%) who had upper extremity pain and 3 of 25 patients (12\%) who had lower extremity pain had removed the implant.

The mean durations between an initiating event and implantation in the removal and non-removal groups were $39.0 \pm 22.3$ months, ranging from 8 to 64 months versus 
Table 1. Comparison of Data between the Removal and Nonremoval Groups

\begin{tabular}{lcc}
\hline & $\begin{array}{c}\text { Removal group } \\
(n=5)\end{array}$ & $\begin{array}{c}\text { Non-removal } \\
\text { group }(n=35)\end{array}$ \\
\hline $\begin{array}{l}\text { Mean age (y) } \\
\text { Sex ratio (M/F) }\end{array}$ & $27.2 \pm 6.4^{*}$ & $43.5 \pm 10.7$ \\
Site of CRPS & $4 / 1$ & $29 / 6$ \\
Upper extremity & & 13 \\
Lower extremity & 3 & 22 \\
Mean durations between an & $39.0 \pm 22.3$ & $39.0 \pm 30.0$ \\
initiating event and & & \\
implantation (m) & & \\
Mean duration of & $34.4 \pm 18.2$ & $38.9 \pm 31.2$ \\
implantation (m) & & \\
Type of CRPS & $5{ }^{\dagger}$ & 22 \\
Type 1 & 0 & 13 \\
Type 2 & $5(100 \%)^{*}$ & 5 (14.3\%) \\
Return to work (\%) & & \\
* $P$ < 0.01. ${ }^{\dagger}$ The removal group was composed of patients with \\
only CRPS type 1, not type 2 $(P<0.01)$. CRPS: complex regional \\
pain syndrome.
\end{tabular}

$39.0 \pm 30.0$ months, ranging from 7 to 120 months.

The mean duration of implantation in the removal group was $34.4 \pm 18.2$ months, ranging from 17 to 59 months. On the other hand, the mean duration of implantation in the non-removal group was $38.9 \pm 31.2$ months, ranging from 7 to 127 months.

The permanent implants could only be removed in $\mathrm{pa}^{-}$ tients with CRPS type 1 [in 5 of 27 (18.5\%) vs. 0 of 13 patients with CRPS type 1 and 2, respectively, $P<0.01$ ] (Table 1).

All 5 patients (100\%) that removed the SCS returned to work; only 5 of 35 patients (14.3\%), who did not remove it returned to work $(P<0.01)$ (Table 1$)$.

\section{DISCUSSION}

Even though this study had a limited number of data, relatively young patients with CRPS type 1 had a better prognosis for complete pain relief after SCS implantation, and could remove the SCS within a 5-year period (17-59 months) and return to their work.

SCS has been shown to reduce pain and improve quality of life within both a 6 -month and 2-year period [4,5]. However, it is difficult for patients who have implanted a permanent SCS to obtain long-term pain coverage for longer than 5 years, even with a successful trial after psychologic assessment [6]. After a gradual reduction and final cessation of medications, the cases where there are no further pain complaints are extremely rare, even after cessation of SCS for 6 months.

Known poor outcome predictors for successful SCS implantation are limited, but include smoking [7], highdose opioid usage [8], psychological factors, such as somatization, depression, anxiety, poor coping, older age, a longer pain duration [9], an implanter with little experience, and incorrect etiologies of patient pain [10].

Pain characteristics for a good candidate for an SCS are steady, burning, lancinating chronic neuropathic pain, not dull, aching nociceptive pain [11]. In addition, in our clinic, patients with CRPS, a benign musculoskeletal sympathetic-maintained pain, could take an anticonvulsant and antidepressant with only weak opioids (tramadol and codeine), without using strong opioids.

In this study, only relatively young patients in their twenties, with the exception of 1 patient aged 39, had a successful removal of the permanent SCS. Young patients may have greater flexibility returning from the disturbance of the sympathetic nervous system [12].

Five of 27 (18.5\%) patients with CRPS type 1 had a successful removal; however, none of 13 patients with CRPS type 2 qualified for removal. CRPS type 1, without nerve injury on the electromyogram/nerve conduction test, had a better prognosis.

In addition, all 5 patients (4 students and 1 sailor) continued their work after a brief period of hospitalization during the implantation period. On the contrary, only 5 of 35 patients, who failed to remove the SCS, had jobs.

It was difficult to find the difference for the prognosis between upper $(2 / 15,13.3 \%)$ and lower $(3 / 25,12 \%)$ extremities. There was no evidence of difference between male $(4 / 33,10 \%)$ and female $(1 / 7,14.3 \%)$ patients. Durations (month) between an initiating noxious event to implantation were variable in the removal group; 8, 25, 48, 50 and 64 months. We could not find the difference of durations between the removal and non-removal group.

There are 3 kinds of insurance coverage in Korea: national health, automobile, and workers' accident compensation insurance. Patients with the latter 2 types of insurance do not have to pay their costs. Four of 24 (16.7\%) and 1 of $12(8.3 \%)$ patients had a successful removal of their SCSs in the health and industrial accident insurance 
groups, respectively. However, the differences among types of insurance were not clear because this study had only a limited number of patients.

In Korea, the 3 major health insurance systems require at least these 3 criteria for SCS implantation; 1) the Budapest clinical diagnostic criteria for CRPS, 2) consultation with a psychologist for the evaluation of depression, compensation, or secondary gain, and 3) a medication history for neuropathic pain with maximal dosage of an anticonvulsant and antidepressant for at least 6 months. All implantation cases were fulfilled these criteria.

In our experience, long-term use of strong opioids (especially, the immediate release type) may hinder discontinuation of all medications and achieving a successful removal of SCSs.

The limitations of this study are the limited data of one hospital and an insufficient duration. However, this study proves a good result in young patients with CRPS type 1.

In conclusion, only young patients with CRPS type 1 could remove a permanent SCS within 5 years and return to work with complete relief of pain, regardless of sex, site of CRPS, mean duration of an initiating event to implantation, mean duration of implantation, and type of insurance in this study.

\section{CONFLICT OF INTEREST}

The authors declare that there is no conflicts of interest and no source of funding.

\section{REFERENCES}

1. Poree L, Krames E, Pope J, Deer TR, Levy R, Schultz L. Spinal cord stimulation as treatment for complex regional pain syndrome should be considered earlier than last resort therapy. Neuromodulation 2013; 16: 125-41.

2. Harden RN, Bruehl S, Perez RS, Birklein F, Marinus J, Maihofner $\mathrm{C}$, et al. Validation of proposed diagnostic criteria (the "Budapest Criteria") for Complex Regional Pain Syndrome. Pain 2010; 150: 268-74.

3. Shin SH, Kim SJ. Bone scintigraphy in patients with pain. Korean J Pain 2017; 30: 165-75.

4. Kemler MA, Barendse GA, van Kleef M, de Vet HC, Rijks CP, Furnée CA, et al. Spinal cord stimulation in patients with chronic reflex sympathetic dystrophy. N Engl J Med 2000; 343: 618-24.

5. Kemler MA, De Vet HC, Barendse GA, Van Den Wildenberg $F A$, Van Kleef $M$. The effect of spinal cord stimulation in patients with chronic reflex sympathetic dystrophy: two years' follow-up of the randomized controlled trial. Ann Neurol 2004; 55: 13-8.

6. Kemler MA, de Vet HC, Barendse GA, van den Wildenberg FA, van Kleef M. Effect of spinal cord stimulation for chronic complex regional pain syndrome Type I: five-year final follow-up of patients in a randomized controlled trial. J Neurosurg 2008; 108: 292-8.

7. De La Cruz P, Fama C, Roth S, Haller J, Wilock M, Lange $S$, et al. Predictors of spinal cord stimulation success. Neuromodulation 2015; 18: 599-602.

8. Sharan AD, Riley J, Falowski S, Pope JE, Connolly AT, Karst $E$, et al. Association of opioid usage with spinal cord stimulation outcomes. Pain Med 2018; 19: 699-707.

9. Celestin J, Edwards RR, Jamison RN. Pretreatment psychosocial variables as predictors of outcomes following lumbar surgery and spinal cord stimulation: a systematic review and literature synthesis. Pain Med 2009; 10: 639-53.

10. Verrills $P$, Sinclair $C$, Barnard A. A review of spinal cord stimulation systems for chronic pain. J Pain Res 2016; 9: 481-92.

11. Deer T, Masone RJ. Selection of spinal cord stimulation candidates for the treatment of chronic pain. Pain Med 2008; 9: S82-92.

12. Hoehn-Saric R, McLeod DR. The peripheral sympathetic nervous system. Its role in normal and pathologic anxiety. Psychiatr Clin North Am 1988; 11: 375-86. 